\title{
Laborer Compressed between the Top Rail of a Scissor Lift Guardrail and a Steel Beam - Massachusetts
}

Release Date: May 22, 2015

Investigation: \# 13-MA-032-01
Massachusetts Department of Public Health Occupational Health Surveillance Program

\section{SUMMARY}

On December 5, 2013, a 37-year-old male laborer (victim) was fatally asphyxiated when his head and neck region was compressed between a steel beam and the top rail of a scissor lift. The victim was working from a raised scissor lift to secure a large tarpaulin (tarp) to a steel column on a construction site. The tarp became caught on the scissor lift's joystick control causing the lift to rise up further unexpectedly and resulting in the compression injuries. Workers from another company found the victim when they went to check on him. A call was placed for emergency medical services (EMS). The local police and EMS arrived at the incident location within minutes. The victim was transported to a local hospital where he was pronounced dead.

Contributing factors identified in this investigation included the tarpaulin being draped across the raised lift's guardrail, working alone from an elevating work platform, and the bar guard design not preventing the tarp from becoming entangled and engaging the joystick.

The Massachusetts FACE Program concluded that to prevent similar occurrences in the future, employers should:

- Develop standard operating procedures (SOPs) for installing tarpaulins from scissor lifts that includes never draping tarpaulins over or across the lift's guardrail; and

- Develop, implement and enforce a policy that prevents employees from working alone when using elevating work platforms.

In addition, equipment manufacturers should:

- Perform comprehensive product assessments based on Prevention through Design (PtD) concept to identify potential hazards and then eliminate these hazards through design changes. 


\section{INTRODUCTION}

On December 6, 2013, the Massachusetts FACE Program was alerted by the local media that on December 5, 2013, a male laborer was fatally injured while using a scissor lift. An investigation was initiated. On February 11, 2014, the Massachusetts FACE Program Director traveled to the company's office location and met with company representatives to discuss the incident. The police report, death certificate, company information, and the OSHA fatality and catastrophe report were reviewed during the course of the investigation.

\section{EMPLOYER}

The employer is a spray-on fireproofing and thermal and acoustic insulation contractor. The company primarily focuses on large commercial and residential projects, both new construction and renovations. The company has been in business for approximately 35 years and has approximately 30 employees. Most of the field employees are laborers and sprayers.

On the day of the incident, the victim's shift started around 6:30 a.m. The victim was part of a work crew of three workers that included two laborers and one sprayer. All of the laborers, including the victim had union representation.

\section{WRITTEN SAFETY PROGRAMS AND TRAINING}

The company had an Injury and Illness Prevention Program (I2P2) and provided employees the OSHA 10-hour training and the OSHA 10-hour refresher course. The content of both the I2P2 and additional training provided by the employer included, but was not limited to, fall protection, hazard communication, scaffolds and lifts. In addition, all newly hired employees were provided with an orientation that included on-the-job training. The company had provided the victim with multiple trainings including the OSHA 10-hour, fall protection, boom lifts, scissor lifts, mobile equipment, and confined space entry. The company had workers' compensation insurance as required by law in Massachusetts (G.L. c. 152, Sec. 25A).

\section{VICTIM}

The victim was a 37-year-old male laborer who had been employed with the company for several years at the time of the incident. Originally from Ireland, he had been living in the United States for multiple years. The day of the incident, a Thursday, the victim arrived to work at 6:30 a.m. and was scheduled to work a full shift.

\section{INCIDENT LOCATION}

The incident occurred on the fourth floor of an eight story building that was in the process of going through a complete renovation (Figure 1). The building was located in the downtown section of a large city and the construction site encompassed an entire city block. At the time of the incident, the inside of the building had been gutted and one entire side of the building's exterior wall was completely open (Figure 2).

\section{EQUIPMENT}

The equipment involved in the incident was an electric powered mobile elevating work platform (scissor lift) that was manufactured in 2005 (Figure 3). The scissor lift was being rented by the insulation company and had been on site for about one month at the time of the incident. The scissor 
lift was battery operated, had four solid rubber tires, and a maximum raised platform height of 19 feet. The lifting mechanism was hydraulic and had a lift time of 25 seconds with a rated load. The lift's capacity was two people and not to exceed a maximum of 550 pounds. The lift was equipped with a tilt alarm that will sound an alarm and prevent movement if the scissor lift is out of level. The overall dimensions of the lift were 32 inches wide by 70 inches long and the lift weighed 2580 pounds. The lift's work platform (operator's area) dimensions were 26 inches wide by 64 inches long. The work platform was equipped with fall protection in the form of guardrails and was also equipped with an anchor point for the attachment of a lanyard as part of a personal fall protection system.

The lift's platform was equipped with a removable control console that was mounted at the right front corner of the platform near the top of the guardrail (Figure 4). This console contains multiple controls, one of which was a joystick that controls lifting, driving direction, speed, and steering functions. The joystick had a trigger switch that energizes the joystick and must be continuously depressed in order to engage the other functions the joystick controls. When the joystick is released, the control automatically goes back to a neutral setting. The console also had an emergency stop button, a horn, battery charging status gauge, a lift/drive off switch, and a joystick bar guard. In addition, the lift had a load sensing system and when the rated load was exceeded a light flashes, an alarm goes off and all electrically controlled platform movements stop until the overload is removed from the platform.

The manufacturer's operators manual for the lift contained multiple warnings. One warning was to avoid overhead obstructions and other possible hazards around aerial platforms when lifting or driving. Another warning was to keep all body parts inside the aerial platform when lifting or driving to avoid crushing injuries.

\section{INVESTIGATION}

The insulation company was hired by the general contractor to apply spray-on fireproofing to the building being renovated. It was estimated to take multiple months to apply the fireproofing to building's eight floors. The fireproofing was a cellulose type of material that's mixed with a liquid on site and then sprayed. Because the process of spraying the fireproofing is messy, typically either an entire floor or a large area of a building's floor would be occupied solely by the insulation company employees.

The victim had been at the work site for the six weeks leading up to the incident and was part of a three person work crew from the insulation company. The work crew was made up of two laborers, which included the victim, and one sprayer. The company reported that on the day of the incident, the main tasks were to prepare the area on the fourth floor for spraying fireproofing, which was planned to take place the following day. Preparing the area included cleaning the floors, cleaning and wrapping and positioning spray hoses and installing large polyethylene tarpaulins (tarps) to protect surrounding areas from overspray.

It was reported by the employer that between 10:00 a.m. and 11:00 a.m. they told the victim's two coworkers to go home for the day and told the victim to clean up around the fourth floor work area and then to go home. This occurred because the project funders were going to tour the building and the construction site that day. The sprayer and the other laborer left the work site and the victim stayed to clean up the area for the walk through. Once the victim finished cleaning the area, it appears that he started to prepare the area for the spraying of fireproofing that was to occur the next day. It was 
suggested by the company that the victim might have stayed and started these other tasks to get a few more hours of work/pay in that day.

As part of the preparation for the next day tasks, the victim was using a scissor lift to install a large polyethylene tarp that would function as a barrier to protect the surrounding areas from overspray. The tarp was being fastened to a steel column located at an exterior wall of the building. This was one of the building's walls that was completely open to the elements. The exterior wall opening where the incident occurred was approximately 13 feet high and 20 feet wide (Figure 2).

At the time of the incident, the victim was alone on the fourth floor of the building, although workers from other subcontractors were performing tasks throughout the building. The victim had the scissor lift positioned at an exterior wall of the building and was working from the lift's raised platform. It appears that the victim, who was wearing a hardhat, at the time of the incident, was leaning out and over the scissor lift's guardrail when the tarp became caught on and around the joystick control lever. The tarp engaged the trigger switch and joystick causing the scissor lift to rise up. The victim's head and neck area were crushed between the scissor lift's guardrail and an overhead steel beam.

At about 2:00 p.m., a pedestrian walking by the construction site noticed the victim in an abnormal position and out of concern asked a worker who was assigned to monitor a gate at the perimeter of the construction site if the victim was okay. This worker yelled to another worker who was working from an aerial lift outside the building's third floor and he raised the aerial lift and noticed that the victim was trapped. The worker in the aerial lift yelled for someone to call for emergency medical services (EMS). The worker then yelled to a worker on the third floor who ran up to the fourth floor as the worker in the aerial lift raised the lift even higher to the fourth floor.

Once the worker who ran up the stairs got to the scissor lift he climbed up the side of the lift and noticed the tarp was draped over the victim's left shoulder and hanging over a section of the lift's guardrail. The tarp was also hanging off the left side of the lift and draped over to the right where it was hung up on the joystick control lever. The worker grabbed the joystick and had to forcefully pull back on the joystick because it was being held in the forward position by the weight of the tarp. Pulling back on the joystick caused the scissor lift to descend to the floor level freeing the victim. The worker who freed the victim along with the worker who was working from the aerial lift brought the scissor lift with the victim on the platform to the construction elevator and used the elevator to bring the scissor lift and the victim to the ground floor. The local police and EMS arrived at the incident location within minutes. Once the elevator reached the ground floor EMS transported the victim to a local hospital where he was pronounced dead.

After the incident the scissor lift went through a complete inspection by both OSHA and the manufacturer and both found that the scissor lift was not defective and functioning normally at the time of the incident.

\section{CONTRIBUTING FACTORS}

Occupational injuries and fatalities are often the result of one or more contributing factors or key events in a larger sequence of events that ultimately result in the injury or fatality. The Massachusetts FACE team identified the following contributing factors in this incident.

- Tarpaulin being draped across and over the lift's guardrail 
- Working alone from an elevating work platform

- Bar guard design not preventing the tarp from becoming entangled and engaging the lift's joystick

\section{CAUSE OF DEATH}

The medical examiner listed the cause of death as mechanical asphyxia with compression of oropharynx.

\section{RECOMMENDATIONS/DISCUSSION}

\section{Recommendation \#1: Employers should develop standard operating procedures (SOPs) for installing tarpaulins from scissor lifts that includes never draping tarpaulins over or across the lift's guardrail.}

Discussion: The scissor lift's operating manual states that materials should not be placed on the guardrails and that materials should not exceed the confines of the guardrails. ${ }^{1,2}$ When the victim was found, a tarpaulin (tarp) was draped over the victim's left shoulder and over sections of the lift's guardrail. The tarp was hanging off the left side of the lift's guardrail and was also draped to the right where it was hung up on the joystick control lever. The joystick was being held in the forward position by the weight of the tarp causing the lift to be stuck in the lifting mode.

Employers should develop standard operating procedures (SOPs) for when employees will be installing large tarps from raised work platforms. Training on the SOPs should be provided to all employees who will be performing this task and to all employees who will be in close proximity while the task is being performed. It is important that SOPs for installing tarps includes that tarps are never to be draped over the work platform guardrails. Tarps should be folded and placed fully within the work platform area until they are ready to be hung. Once the lift is in the desired location then the tarp should be lifted out over the guardrail and a section of the tarp fastened in the desired location. Then the rest of the tarp should be dropped to the floor below. Next, the lift can be repositioned to continue securing the tarp. This process should be repeated until the entire tarp has been completely secured.

\section{Recommendation \#2: Employers should develop, implement and enforce a policy that prevents employees from working alone when using elevating work platforms.}

Discussion: At the time of the incident, the victim's two co-workers were told to go home for the day. The victim was assigned to first clean up around the fourth floor of the worksite and then to go home. Once the co-workers left, the victim was the only employee from his company remaining at the worksite. Workers from other subcontractors were on site, but none of these workers were on the fourth floor with the victim. After completing the cleaning task, the victim started to perform some additional tasks to prepare the work location for the spraying that would occur on the following day. It was at this point that the victim started using the scissor lift.

A policy that prohibits employees from working alone when using elevating work platforms should be developed by employers. ${ }^{3,4}$ The policy could include other potentially hazardous tasks that should not be performed alone. Employers who send their employees out to job sites should carefully consider the tasks their employees will be performing on these sites as well as the tasks workers from other employers will be performing on these sites for potential hazards. 
If the company had a policy that prohibited working alone from elevating work platforms, the victim might have not started the task of hanging the tarp, because this task required the use of a scissor lift. The policy could also increase the chance that help would be summoned as quickly as possible by the second worker if an incident was to occur. In this case, because the cause of death was mechanical asphyxia with compression of oropharynx, if a co-worker was present with the victim, this co-worker might have been able to quickly assist the victim. The co-worker could have used the lift's emergency lowering system to lower the scissor lift from the overhead steel beam, freeing the victim and potentially stopping the asphyxia. Then the co-worker could have placed a call to emergency medical services, resulting in quick medical attention.

\section{Recommendation \#3: Equipment manufacturers should perform comprehensive product assessments based on Prevention through Design (PtD) concept to identify potential hazards and then eliminate these hazards through design changes.}

Discussion: Prevention through Design (PtD), as it would relate to equipment manufacturers, involves addressing occupational safety and health needs during the design process to eliminate or minimize injury. ${ }^{5}$ PtD initiates thinking about how the equipment functions in relation to individuals that would come in contact or interact with the equipment in order to identify potential hazards. Once hazards are identified, the equipment can be designed to eliminate or control these hazards.

In this case, the manufacturer had equipped the control console with a joystick trigger switch and a bar guard. These features were developed to prevent the joystick control from being un-expectantly engaged, but the tarp was still able to become entangled on the joystick causing the lift to rise unexpectantly. The scissor lift, which is still being manufactured with the same features, serves as an excellent example of the potential for eliminating or minimizing injury risks through a comprehensive $\mathrm{PtD}$ review of the equipment.

If PtD was applied to the scissor lift, the potential for the worker and equipment interaction that led to the incident could have been identified and highlighted the need to redesign and/or incorporate additional engineering controls to the control console. For example, the control console could have been redesigned with a guard or shield that encompasses the entire joystick, which would better prevent an un-expectant engagement of the lift's joystick. PtD could also have led to a more advanced load sensing system, such as a system that can detect when a lift's guardrail is up against a stationary object while its controls are still engaged. The system could then sound an alarm and lower the work platform a few inches; this could have possibly limited the victim's injuries.

In addition, there are multiple articulating aerial lift manufacturers that have developed systems to prevent lift operators from sustaining injuries resulting from being crushed between the work platform guardrail and stationary objects. Other manufacturers have developed similar aftermarket systems to prevent these types of crushing hazards. The technology used in these safety systems for articulating aerial lifts could be used as the basis in the development of similar systems for scissor lifts.

\section{REFERENCES}

1. Skyjack operating manual 157924AF-A, February 2014, www.skyjack.com/sites/default/files/documents/uploaded/1308938659655/157924.pdf 
2. American National Standards Institute, ANSI/SIA-A92.6 (2006) Self-Propelled Elevating Work Platforms, http://www.ppsa.org/assets/TechnicalReferences/self_propelled_elevating_work_platforms.pdf

3. Insulation Outlook, March 2014, Safety Procedures for Employees Working Alone, www.insulation.org/io/article.cfm?id=IO140302

4. WorkSafeBC, Working Alone: A Handbook for Small Businesses, 2012, www.worksafebc.com/publications/health_and_safety/by_topic/assets/pdf/bk131.pdf

5. National Institute for Occupational Safety and Health, Workplace Safety \& Health Topics, Prevention Through Design. www.cdc.gov/niosh/topics/ptd

Figure 1 - Building where incident occurred

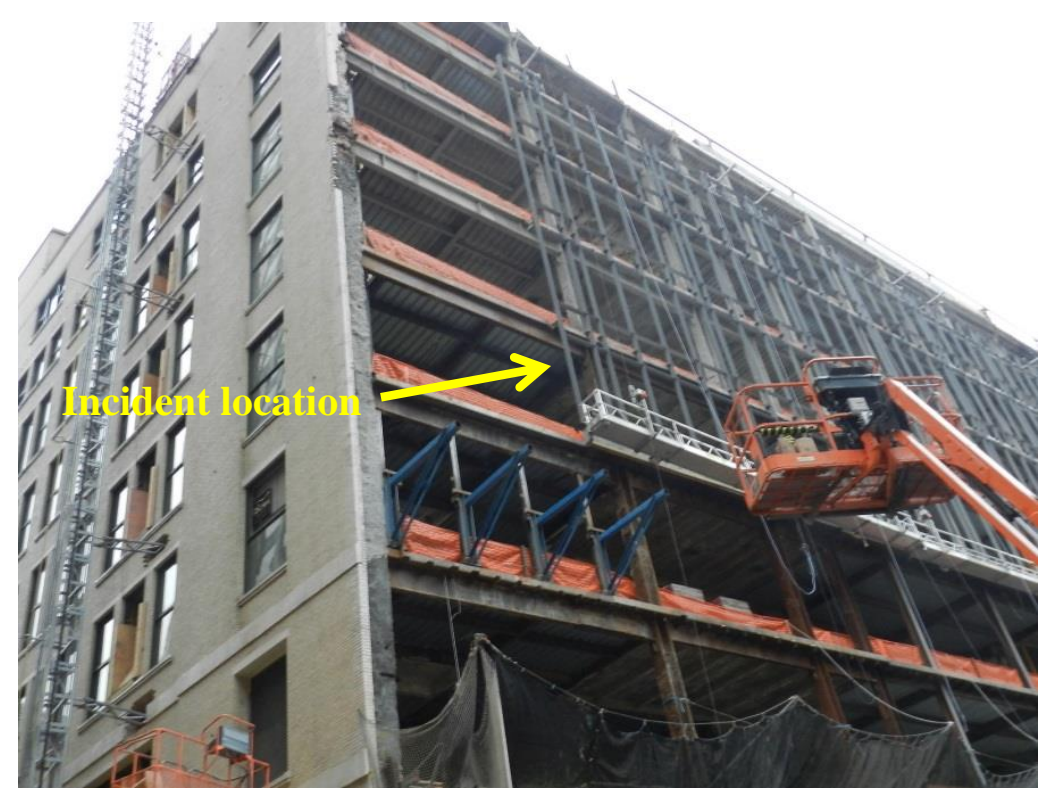


Figure 2 - Location where scissor lift was positioned

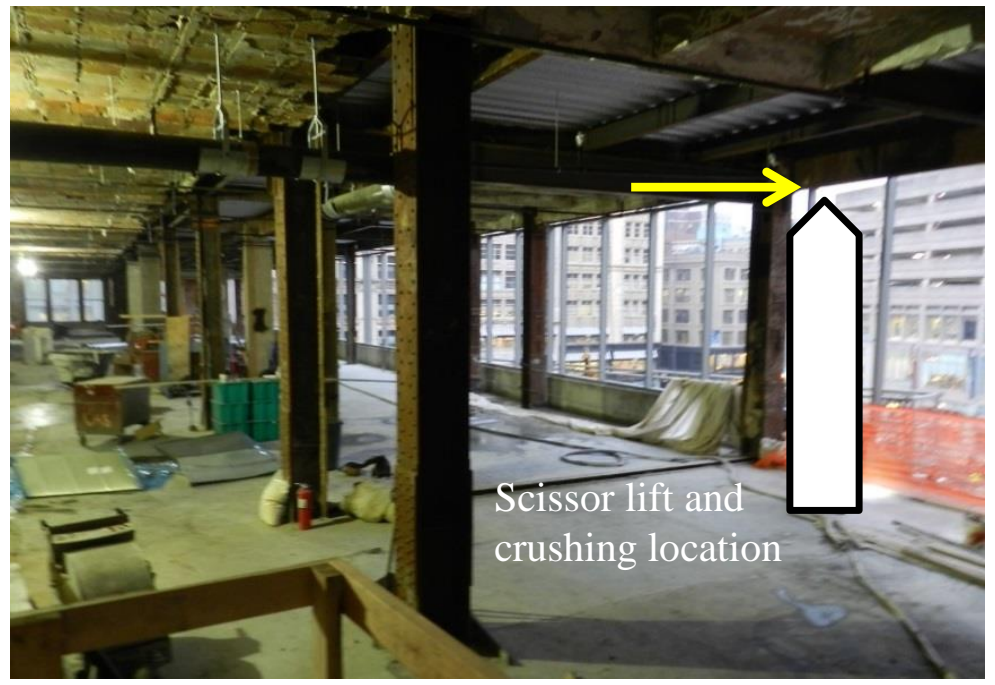

Figure 3 - Scissor lift involved in the incident

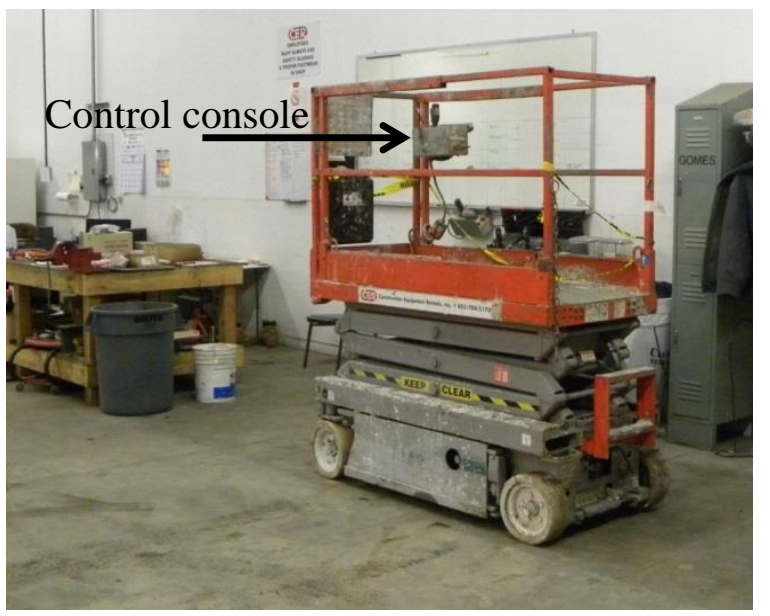


Figure 4 - Scissor lift control console
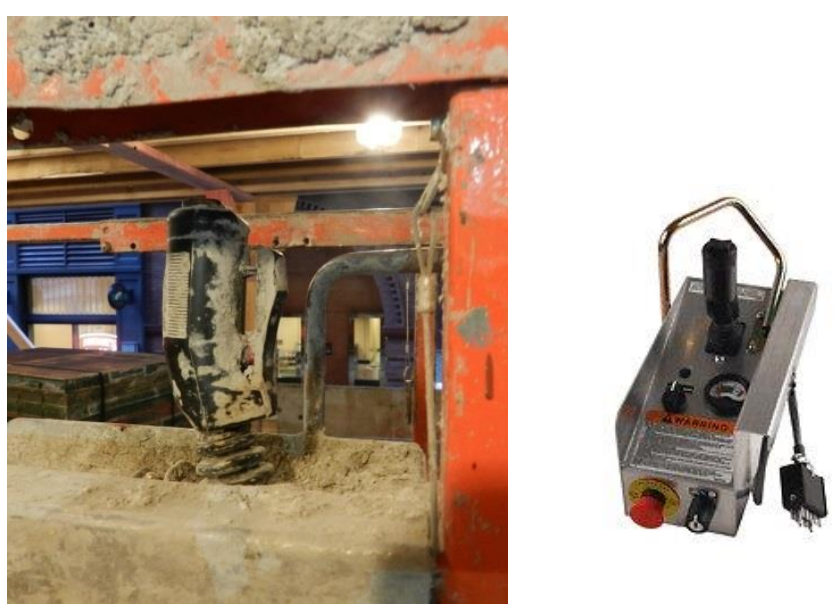